\title{
Helen Salisbury: Poaching in practice
}

\author{
Helen Salisbury GP \\ Oxford
}

It's uncontroversial to suggest that GP workloads have increased over the past 10 years. ${ }^{12}$ Work previously done in hospitals has shifted to primary care, and the population of older patients with complex medical needs has grown. Demand has risen, and patients have higher expectations of instant access. When I first started in general practice few people had mobile phones and, unless they were sick enough to stay in their homes, most patients didn't ask to be called.

For stressed GPs, however, help is at hand. August is the end of the training year, and a newly minted batch of qualified GPs will shortly join the workforce. They're hugely welcome, and competition for their services is hot. But many new GPs are anxious about taking on the responsibility for a list of patients, and relatively few commit straight away. And who can blame them, when there are many other well remunerated and far less onerous ways of using their skills?

In addition to plentiful locum work, every five minutes seems to bring another initiative from on high that takes GPs away from their core role of being the named doctor for a group of patients. They now work at the front door of hospitals, filtering out patients who should see a GP rather than attend the emergency department. ${ }^{3}$ The promise of seven day access to routine primary care, which seemed to be politically driven rather than based on need, means that patients can see an unfamiliar doctor on a Sunday afternoon but can't see their own doctor for a month, as their registered practice is understaffed and can't recruit. ${ }^{45}$

Seeing another doctor who has access to your primary care record is nowhere near as good as seeing your own. Your GP already knows your history and doesn't have to spend half the appointment glued to the computer, looking at your notes. Your GP remembers what happened last time you went to hospital and can help you weigh up the likely risks and benefits of another referral. Your GP will read your letters, be alert to abnormal test results, oversee your prescriptions, and liaise with other services on your behalf.

But, as list sizes climb, this role becomes more onerous, and the prospect of holding such responsibility becomes less inviting. ${ }^{67}$ We're losing older colleagues to early retirement, and the new Primary Care Network directorships will remove another 250 or so full time equivalent GPs from the system, leaving the remainder increasingly stretched.

Knowing patients over time, treating whole families, earning their trust and confidence- these are the joys of general practice. But we need list sizes to be manageable so that this feels like a privilege rather than a burden. GPs are a multi-talented and versatile group, but please can we employ them where they're most needed-in routine, day-to-day general practice?

Competing interests: See www.bmj.com/about-bmj/freelance-contributors.

Provenance and peer review: Commissioned; not externally peer reviewed.

1 Hobbs FDR, Bankhead C, Mukhtar T, etal. National Institute for Health Research School for Primary Care Research. Clinical workload in UK primary care: a retrospective analysis of 100 million consultations in England, 2007-14. Lancet 2016;387:2323-30 10.1016/S0140-6736(16)00620-6 27059888

2 Institute for Government. Performance tracker 2018: general practice. https://www. instituteforgovernment.org.uk/publication/performance-tracker-2018/general-practice.

3 Bostock N. Every A\&E will have GPs on front door by Christmas, says Simon Stevens. GP 2017 Mar 9. https://www.gponline.com/every-a-e-will-gps-front-door-christmas-sayssimon-stevens/article/1426992.

4 NHS England. Improving access to general practice. https://www.england.nhs.uk/gp/gpfv/ redesign/improving-access/.

5 Matthews-King A. GP vacancies rise to record levels despite recruitment pledge, survey suggests. Independent $2018 \mathrm{Jul} 6$. https://www.independent.co.uk/news/health/gp-vacancynhs-70-doctors-waiting-times-appointments-patient-safety-a8433596.html.

6 Gault B. Number of registered patients per GP rises to almost 2100. Pulse 2019 Jul 11. http://www.pulsetoday.co.uk/news/all-news/number-of-registered-patients-per-gp-risesto-almost-2100/20039037.article.

7 Badshah N. Average family doctor has 2187 patients. Times 2019 Jul 29. https://www. thetimes.co.uk/article/average-family-doctor-has-2-187-patients-mtgvdx6jq? shareToken=2e80d597a1950daccbc6e6c5e1541a63.

Published by the BMJ Publishing Group Limited. For permission to use (where not already granted under a licence) please go to http://group.bmj.com/group/rights-licensing/ permissions 